\title{
Komunikasi Interpersonal Antara Relawan Dengan Anak Marginal Dalam Mendorong Minat Belajar di Save Street Child Pondok Ranji, Tangerang Selatan
}

\author{
Stefani Kurniati Setiawan, Widayatmoko \\ Stefanikurniati11@gmail.com,widayatmoko@fikom.untar.ac.id \\ Fakultas Ilmu Komunikasi Universitas Tarumanagara
}

\begin{abstract}
Save Street Child is an independent organization that prepares marginal children who have minimal access to education in order to be an adequate successor through education and good friends. Save Street Child has several classes in various cities. One of them is in Pondok Ranji, South Tangerang. The formulation of the problem in this research is how interpersonal communication between volunteers and marginal children in encouraging learning interest in Save Street Child Pondok Ranji, South Tangerang. The purpose of this study was to determine interpersonal communication between volunteers and marginal children in encouraging learning interest. The theory or concept used in this study are interpersonal communication, the effectiveness of interpersonal communication, communication in the teaching and learning process, and interest in learning. The type of research used in this study is descriptive qualitative research with a case study research strategy. The conclusion of this study is that by using interpersonal communication, the personality of a marginal child becomes open so that when the openness arises, a sense of pleasure can encourage children's learning interest. In addition, the interest in learning is also encouraged because the given lessons make marginal children interested in paying attention to the classroom.
\end{abstract}

Keywords: interpersonal communication, interest in learning, marginal, volunteers

\begin{abstract}
Abstrak
Save Street Child adalah sebuah organisasi independen yang mempersiapkan anak marginal yang memiliki akses pendidikan yang minim supaya dapat menjadi penerus bangsa yang memadai melalui pendidikan dan teman baik. Save Street Child mempunyai beberapa kelas di berbagai kota. Salah satunya berada di Pondok Ranji, Tangerang Selatan. Rumusan masalah dalam penelitian ini adalah bagaimana komunikasi interpersonal antara relawan dan anak marginal dalam mendorong minat belajar di Save Street Child Pondok Ranji, Tangerang Selatan. Tujuan dalam penelitian ini adalah untuk mengetahui komunikasi interpersonal antara relawan dengan anak marginal dalam mendorong minat belajar. Teori atau konsep yang digunakan adalah komunikasi interpersonal, efektivitas komunikasi interpersonal, komunikasi dalam proses belajar mengajar, dan minat belajar. Jenis penelitian yang digunakan adalah penelitian kualitatif deskriptif dengan strategi penelitian studi kasus. Temuan dalam penelitian ini adalah komunikasi interpersonal yang digunakan oleh relawan kepada anak marginal telah mendorong minat belajar anak marginal di kelas Save Street Child Pondok Ranji, Tangerang Selatan. Kesimpulan dari penelitian ini ialah dengan menggunakan komunikasi interpersonal, kepribadian anak marginal menjadi terbuka sehingga dari keterbukaan tersebut timbul-lah rasa senang yang dapat mendorong minat belajar anak. Selain itu, terdorongnya minat belajar tersebut juga dikarenakan oleh pelajaran yang diberikan membuat anak marginal tertarik untuk memperhatikan pengajaran di kelas.
\end{abstract}

Kata kunci: komunikasi interpersonal, minat belajar, marginal, relawan 


\section{Pendahuluan}

Pendidikan merupakan salah satu hal penting dalam kehidupan manusia. Sudah menjadi hal umum bila orang tua ingin memberikan yang terbaik untuk anaknya terutama dalam pendidikan. Bahkan sejak masih kecil, anak diberikan pendidikan secara informal oleh orang tuanya di rumah. Seperti merangkak, mengucapkan terima kasih ketika menerima sesuatu, berdoa sebelum melakukan aktivitas dan lain sebagainya.

Namun, ada beberapa orang tua yang tidak mampu untuk menyekolahkan anaknya karena himpitan ekonomi. Imbas dari permasalahan ekonomi kebanyakan menyinggung pendidikan anak-anak, sehingga tidak sedikit keluarga yang tinggal pada pemukiman marginal merasa tidak mampu untuk menyekolahkan anak-anak (Putro dalam Husna, 2018).

Kaum marginal merupakan kaum pra-sejahtera. Kaum marginal identik dengan masyarakat miskin dan terpinggirkan. Penghasilannya pas-pasan bahkan sering mengalami kekurangan. Pengemis, pemulung, buruh dan sebagainya merupakan contoh-contoh pekerjaan yang dimiliki oleh kaum marginal. Kondisi seperti inilah yang menyebabkan kehidupan dari kaum marginal tersebut lebih banyak dihabiskan di jalanan daripada di rumah.

Save Street Child adalah sebuah organisasi yang berawal dari gerakan di media massa yang diinisiasi oleh Shei Latiefah. Melalui akun @ savestreetchild, 23 Mei 2011 yang lalu, gerakan ini bermetamorfosis menjadi sebuah organisasi independen yang mempersiapkan anak-anak marjinal yang memiliki akses pendidikan minim supaya dapat menjadi generasi penerus bangsa bekal yang memadai: pendidikan dan teman baik. Kita memberi apa yang telah kita terima. Tugas manusia terdidik adalah mendidik manusia lainnya. Atas dasar itulah, Save Street Child lahir dan menjadi wadah bagi kaum muda untuk berbagi. (http://ictforhumanity.or.id/pages/save-streetchild, diakses pada tanggal 21 November 2018, jam 23.55 WIB).

Untuk itu, sangat penting bagi seseorang yang dengan tulus mengajar anak-anak yang tidak dapat bersekolah, untuk dapat berkomunikasi secara pribadi dengan baik dalam proses pengajarannya agar para anak marginal tersebut merasa didorong untuk memiliki minat belajar yang berguna bagi masa depannya. George R.Terry (dalam Harapan dan Ahmad, 2017) menyatakan bahwa komunikasi merupakan cara untuk memudahkan kegiatan manajemen, termasuk dalam hal ini manajemen pembelajaran. Selain itu, relawan harus membangun komunikasi yang baik dengan anak marjinal dalam pengajarannya agar dapat mendorong minat belajar karena, sebab orang berkomunikasi, ialah untuk mempengaruhi orang lain, membangun atau mempertahankan hubungan antarpersonal, memperoleh berbagai pengetahuan, membantu orang dan komunikasi untuk bermain (Liliweri, 2015). Rumusan masalah dari penelitian ini adalah "bagaimana komunikasi interpersonal antara relawan dengan anak marginal dalam mendorong minat belajar di Save Street Child Pondok Ranji, Tangerang Selatan ?"

Konsep dan teori yang digunakan dalam penelitian ini adalah komunikasi interpersonal dan minat belajar. Menurut Handoko (dalam Ngalimun, 2017) mengatakan bahwa komunikasi adalah proses pemindahan pengertian dalam bentuk gagasan atau informasi dari seseorang ke orang lain, yang melibatkan lebih dari sekedar kata-kata yang digunakan dalam percakapan, tetapi juga ekspresi wajah, intonasi, titik putus lokal dan sebagainya. Kemudian, dalam penelitian ini, peneliti juga 
menggunakan teori/konsep efektifitas komunikasi interpersonal. Menurut Devito (2010), terdapat lima kualaitas umum yang dipertimbangkan dalam berkomunikasi secara interpersonal, yaitu keterbukaan, empati, sikap mendukung, sikap positif, dan kesetaraan. Sedangkan minat belajar adalah suatu perasaan senang, perhatian dalam belajar dan adanya ketertarikan siswa kepada pelajaran yang dilakukan oleh seseorang sehingga menimbulkan perubahan tingkah laku yang berbeda antara sesudah belajar dan sebelum belajar (Wasti, 2013).

\section{Metode Penelitian}

Pendekatan penelitian yang digunakan ialah pendekatan penelitian kualitatif deskriptif. Metode penelitian yang digunakan adalah metode penelitian studi kasus. Menurut Cresswell (dalam Gunawan, 2014), penelitian studi kasus adalah penelitian yang dilakukan terhadap suatu obyek, yang disebut sebagai kasus, yang dilakukan secara seutuhnya, menyeluruh dan mendalam dengan menggunakan berbagai macam sumber data.

Subyek dalam penelitian ini adalah relawan dan anak marginal. Terdapat tiga orang relawan dan tiga orang anak marginal yang diwawancarai. Relawan tersebut bernama Rizky Kuriawan sebagai kepala sekolah kelas dan salah satu pendiri kelas Save Steet Child Pondok Ranji, HS dan Resti, sebagai relawan yang sudah mengajar selama kurang lebih satu tahun. Sedangkan anak marginal yang diwawancarai ialah Mawar, Alvita dan Devina.Kemudian obyek dalam penelitian ini adalah komunikasi interpersonal dan minat belajar.

Metode pengumpulan data yang digunakan dalam penelitian ini dibagi menjadi dua. Pertama, untuk mengumpulkan data primer, penulis melakukan observasi dan wawancara. Kedua, untuk mengumpulkan data sekunder, penulis melakukan studi kepustakaan, dan melakukan penelusuran data online (internet). Untuk teknik pengolahan data, penulis menggunakan langkah-langkah dari Miles dan Huberman (dalam Sugiyono, 2016), yaitu reduksi data (data reduction), penyajian data (data display), kesimpulan / verifikasi (conclusion drawing/verification).

Kemudian, untuk teknik keabsahan data, penulis menggunakan triangulasi sumber. Menurut Denzin (dalam Gunawan, 2014), triangulasi sumber berarti membadingkan (memeriksa ulang) informasi yang diperoleh melalui sumber yang berbeda. Misalnya membandingkan hasil pengamatan dengan wawancara, membadingkan aoa yang dikatakan scara umum dengan yang dikatakan secara pribadi atau membbadingkan hasil wawancara dengan dokumen yang ada.

\section{Hasil Temuan dan Diskusi}

Komunikasi antarpribadi adalah komunikasi yang terjadi secara dialogis, dimana saat seorang komunikator berbicara maka akan terjadi umpan balik dari komunikan sehingga terdapat interaksi. (Stevani dan Widayatmoko, 2017). Hal ini juga terjadi antara relawan dengan anak marginal dalam kelas Save Street Child Pondok Ranji, Tangerang Selatan. Kelas Pondok Ranji berdiri pada tahun 2013 awal oleh lima orang relawan yang sedang mengikuti sebuah training batch yang diadakan oleh Save Street Child. Save Street Child adalah sebuah organisasi yang mempersiapkan anak-anak marginal yang memiliki akses pendidikan yang minim agar dapat menjadi penerus bangsa yang memadai melalui pendidikan yang diajarkan oleh para relawan. 
Komunikasi merupakan suatu hal yang penting. Hal ini diungkapkan oleh para relawan dengan tujuan agar pesan yang diberikan dapat tersampaikan dengan baik. Pesan tersebut disampaikan secara face to face atau tatap muka. Selain itu, untuk melakukan pendekatan kepada anak marginal dengan tujuan mengetahui karakteristik dan kepribadian masing-masing anak, para relawan menggunakan komunikasi secara pribadi atau komunikasi interpersonal. Berkomunikasi secara interpersonal akan berhasil jika komunikasi tersebut dilakukan secara efektif. Menurut DeVito (2010), terdapat lima kualitas umum dalam efektivitas komunikasi antarpribadi. Diantaranya adalah sebagai berikut:

\section{Keterbukaan}

Setiap anak mempunyai sifat dan kepribadian yang berbeda. Ada anak yang mempunyai kepribadian terbuka dan ada anak yang mempunyai kepribadian tertutup. Untuk berkomunikasi secara interpersonal, maka antara komunikator dan komunikan harus mempunyai sifat yang terbuka satu sama lain. Untuk anak yang mempunyai sifat terbuka, maka anak tersebut tidak akan segan-segan untuk menceritakan permasalahannya kepada para relawan. Hal yang sering diceritakan ialah permasalahan dengan temannya di sekolah maupun di kelas Pondok Ranji sendiri. Kemudian untuk anak yang lebih tertutup, maka para relawan akan mendekati anak itu secara pribadi sehingga ketika anak tersebut merasa nyaman dengan para relawan, maka secara perlahan, anak tersebut akan terbuka dengan para relawan tersebut. Keterbukaan inilah yang membuat komunikasi interpersonal dapat berjalan dengan lancar.

\section{Empati}

Empati digunakan untuk menumbuhkan kepercayaan antara komunikator dengan komunikan. Munculnya kepercayaan antara relawan dengan anak marginal terlihat pada salah satu anak yang ketika di kelas, ia menimbulkan suatu masalah. Anak tersebut bernama Aceng. Aceng adalah anak yang hyperactive. Suatu saat, di tengah kelas berlangsung, ia memukul seorang anak perempuan hingga anak tersebut menangis. Aceng sudah disuruh untuk meminta maaf. Namun, ia menolaknya. Di akhir pengajaran, ia terlihat menyendiri. Relawan yang mengetahui kepribadiannya pun mengerti dan memberikan waktu untuk Aceng menenangkan diri. Hingga akhirnya, salah seorang relawan bernama Rizky mendatanginya dan membujuknya untuk berkumpul lagi bersama teman-temannya serta tidak memaksa untuk meminta maaf, karena Rizky tahu bahwa Aceng telah merasa dipojokkan karena telah bersalah memukul teman perempuannya. 


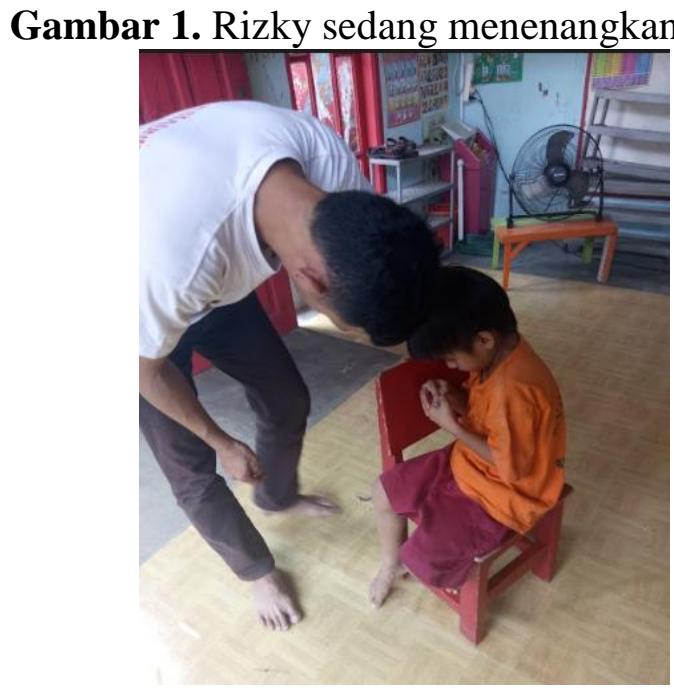

Sumber: Dokumentasi Pribadi

\section{Sikap mendukung}

Sikap mendukung juga ditunjukkan oleh para relawan. Para relawan tersebut menyebutkan bahwa terkadang jika tugas yang diberikan oleh guru di sekolah itu ternyata salah, sedangkan anak murid merasa sudah benar mengerjakannya, maka anak murid berhak untuk mendapatkan penjelasan. Jika tidak didapatkan, maka para relawan akan membantu dan mendukung anak marginal untuk mendapatkan haknya berupa penjelasan mengenai tugas yang diberikan oleh guru di sekolah.

\section{Sikap positif}

Sikap positif juga ditunjukkan oleh relawan ketika menghadapi suatu masalah di dalam kelas seperti adanya anak yang tidak mau mengikuti pelajaran. Contohnya, seorang anak bernama Hengki. Pada dasarnya, ia tidak bersekolah. Sehingga, ia sering tidak taat kepada peraturan yang ada. Namun, daripada memarahinya dan memaksanya untuk mengikuti pelajaran, Resti, salah satu relawan menyebutkan bahwa ia lebih memilih untuk mengikuti kemauan Hengki. Karena pada akhirnya, secara perlahan, Hengki lah yang akan berbalik mengikuti kemauan dari para relawan.

\section{Kesetaraan}

Dalam kelas yang diadakan setiap hari Minggu dan dihadiri oleh 20-30 anak marginal, tidak ada perbedaan perlakukan antara anak marginal yang satu dengan anak marginal yang lainnya. Semuanya sama dan tidak ada yang dibedakan. Hanya saja penangannya yang dibedakan. Misalkan, jika ada anak yang susah untuk diatur, maka para relawan akan lebih ekstra untuk membuat anak tersebut agar dapat diatur. Bahkan di sisi lain, relawan tidak membedakan antara dirinya dengan anak murid. Para relawan menganggap anak marginal bukan sebagai murid namun sebagai teman yang dapat saling belajar satu sama lain.

Terdorongnya minat belajar juga tidak lepas dari adanya rasa senang, perhatian dalam belajar, dan ketertarikan pada materi pelajaran. Perasaan senang didapatkan ketika anak marginal sudah senang dengan keadaan kelas yang diciptakan serta ketika anak tersebut sudah merasa nyaman untuk berkomunikasi secara interpersonal kepada para relawan. Sehingga ketika mengikuti kelas pun, anak tidak akan merasa adanya 
beban dan tekanan yang disebabkan oleh ketidakmampuannya untuk mengeluarkan isi hatinya kepada para relawan.

Gambar 2. Anak-anak marginal sedang menghias paperbag

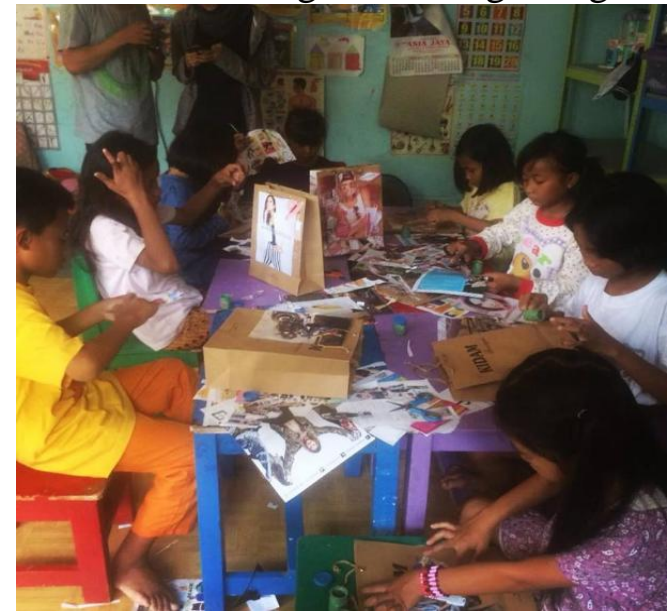

Sumber: Facebook Save Street Child

Kemudian, materi pelajaran yang diberikan juga menyenangkan. Karena pendidikan yang diberikan adalah pendidikan nonformal, maka pelajaran yang diberikan ialah lebih untuk mengasah keterampilan anak-anak. Anak-anak pun sangat menyukainya sehingga setiap minggu sekitar 20-an anak akan datang untuk mengikuti pelajaran yang diberikan. Contoh pelajaran keterampilan yang diberikan ialah menggambar, mewarnai, menghias paperbag, membuat kartu ucapan sekreatif mungkin, dan lain sebagainya.Lalu, dari observasi yang dilakukan, terlihat bahwa anak-anak sangat memperhatikan para relawan ketika memberikan pengajaran atau arahan. Seperti yang terlihat pada gambar di bawah ini:

Gambar 3. Relawan memberikan instruksi kepada anak-anak marginal

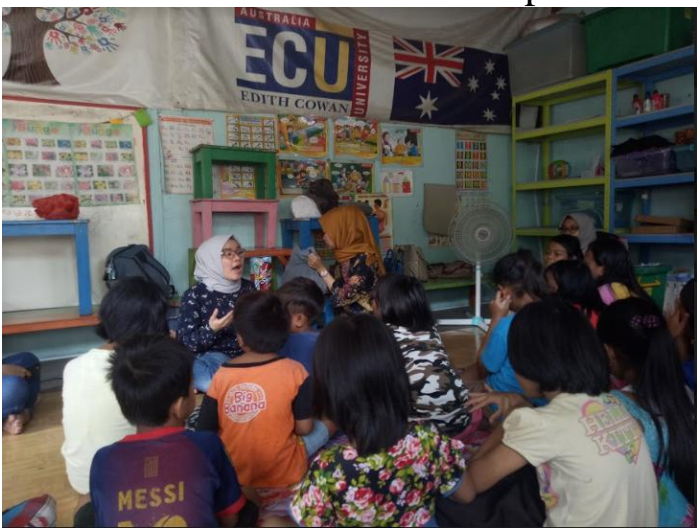

Sumber: Dokumentasi Pribadi

\section{Simpulan}

Komunikasi yang terjalin antara relawan dengan anak marginal di kelas Pondok Ranji, Tangerang Selatan adalah komunkasi interpersonal. Komunikasi yang dilakukan oleh para relawan dalam proses belajar mengajar di kelas Pondok Ranji sudah sangat baik dan efektif. Hal ini dikarenakan materi pembelajaran yang diberikan telah disesuaikan dengan keadaan anak marginal, kemudian relawan sudah dapat 
menangani setiap anak marginal dalam proses belajar mengajar melalui karakteristik dan kepribadian anak marginal, dan sikap serta perilaku dari anak didik (marginal) mengalami perubahan ke arah yang lebih baik. Komunikasi interpersonal antara relawan dan anak marginal telah mendorong minat anak marginal untuk belajar di kelas Pondok Ranji. Hal ini dikarenakan dengan adanya sikap keterbukaan, sikap positif, sikap mendukung, empati dan kesetaraan di antara relawan dengan anak marginal membuat anak marginal merasa senang untuk mengikuti kelas, materi pelajaran telihat menarik dan memperhatikan relawan ketika sedang mengajar. Hingga akhirnya muncullah minat anak marginal untuk belajar di Save Street Child Pondok Ranji, Tangerang Selatan.

\section{Ucapan Terima Kasih}

Dalam penelitian ini, penulis ingin mengucapkan terima kasih kepada: Drs. Widayatmoko, M.M., M.Ikom, selaku dosen pembimbing penulis; keluarga, yang telah memberikan dukungan dan fasilitas; Kak Rizky, Kak Resti, HS, Mawar, Alvita dan Devina, selaku narasumber penulis; Devita, Fasa, Dhea, Wilson, Ferlita, Iren yang membantu penulis menyusun penelitian.

\section{Daftar Pustaka}

Devito, Joseph A. (2010). Komunikasi Antarmanusia (Edisi Kelima). Jakarta: Karisma Publishing.

Gunawan, Imam. (2014). Metode Penelitian Kualitatif Teori \& Praktek. Jakarta: Bumi Aksara.

Harapan, E., \& H. Syarwani Ahmad. (2014). Komunikasi Antarpribadi. Jakarta: PT RajaGrafindo Persada.

Husna, Fathayatul. (2018). Inovasi Pendidikan Pada Kaum Marginal. Jurnal Sosiologi USK, 12(1). 41

Liliweri, Alo. (2015). Komunikasi Antar Personal. Jakarta: Kencana.

Ngalimun. (2017). Ilmu Komunikasi Sebuah Pengantar Praktis. Yogyakarta: Pustaka Baru Press

Pelajaran Tata Busana Di Madrasah Aliyah Negeri 2 Padang. E-Journal Home Economic and Tourism, 2(1).

Stevani, \& Widayatmoko. (2017). Kepribadian Dan Komunikasi Susi Pudjiastuti Dalam Membentuk Personal Branding. E-journal Universitas Tarumanagara, 9(1).

Sugiyono. (2016). Metode Penelitian Kuantitatif, Kualitatif, dan R\&D. Bandung: Alfabeta.

Wasti, S. (2013). Hubungan Minat Belajar Dengan Hasil Belajar Mata. 